\title{
Organizational and economic feasibility of construction projects through the perfection of construction scheduling
}

\author{
Nadezhda A. Stashevskaya ${ }^{1, *}$, Makhmud Kharun ${ }^{1}$, Dmitry D. Koroteev ${ }^{1}$, Maria L. Kunitsyna ${ }^{1}$, Andrey N. Zharov ${ }^{2}$ \\ ${ }^{1}$ Department of Civil Engineering, RUDN University, Moscow, Russia \\ 2Department of Technosphere Safety, RUDN University, Moscow, Russia
}

\section{A R T I C L E I N F O}

\section{Article history:}

Received 19 January 2017

Received in revised form

23 July 2017

Accepted 27 July 2017

\section{Keywords:}

Construction scheduling

Simple technological processes

Construction cost

Planning optimization

\begin{abstract}
A B S T R A C T
Experience of the countries with stable market economy shows that the economic efficiency of construction depends on the organization of works based on the work schedules. In schedules the minimum indicators of value of works and period of their realization depend on the appropriate distribution of manpower and technical resources. Primary problems of reducing the construction cost, while maintaining its high quality are: timeliness of input of objects in operation and improvement of the work organization. Our studies have been aimed at a project cost reduction by optimizing the scheduling and organization of the construction process, i.e., through the development and application of the most efficient models of construction operations management considering the works at the level of simple technological processes and using the modern software products was done. According to the results of study the cost-effective methods are suggested to improve the construction scheduling. The improved methods of construction scheduling by considering the works at the level of simple technological processes can improve the organizational and economic feasibility of construction projects.
\end{abstract}

(C) 2017 The Authors. Published by IASE. This is an open access article under the CC BY-NC-ND license (http://creativecommons.org/licenses/by-nc-nd/4.0/).

\section{Introduction}

Construction schedules are the organizational and technological documents, which set the purposeful sequence of construction of the start-up complexes over time, the sequence and the deadlines for technological steps and implementation of technological complexes in the construction. According to the construction schedules the coordination of all works in the construction projects and their complexes are committed (Taillandiera et al., 2015). Drawing up of the construction schedules is a prerequisite for the accurate, continuous and coordinated work of construction companies and their structural units involved in the construction projects and their complexes. Special attention is paid to work-out of construction schedules for complexes of high-rise residential buildings, industrial buildings of special responsibility and complexity, construction projects that will be erected in cramped conditions. Working-out of the

\footnotetext{
* Corresponding Author.

Email Address: nastashevskaya1@yandex.ru (N. A. Stashevskaya) https://doi.org/10.21833/ijaas.2017.010.004

2313-626X/C) 2017 The Authors. Published by IASE.

This is an open access article under the CC BY-NC-ND license

(http://creativecommons.org/licenses/by-nc-nd/4.0/)
}

construction schedules by the contractors is a multifactorial task. To solve this problem, it is necessary to take into account the multivariance of applied construction technologies, and also resources and capacities of subcontractors. Therefore, in order to minimize the costs, the contractor has to work-out all possible activities that directed to the resource-saving of construction process. These are the principles of sustainable market and it determines the task setting of all types of resource saving in scheduling by optimizing the allocation of resources. It seems appropriate to consider the task of ensuring the timely commissioning of projects by improving the scheduling practices by accounting the works at the level of simple technological processes.

\section{Analysis of the stated issue}

The main task of construction scheduling is to create conditions for the effective implementation of construction work. It is achieved in the implementation of preparatory, construction, finishing and commissioning works in scheduled timing. The boundary factors in scheduling are the technical requirements of works and limitations on the available manpower, material and financial 
resources. Availability of alternative technical solutions and resources, as well as boundary factors to consider when choosing them, allows us to obtain the input data (Fig. 1). On the basis of input data, it is possible to build a model to describe the planning and management of the construction process. The ultimate goal of creating such model is to obtain an output product: buildings, structures or complexes in the shortest time (Stashevskaya et al., 2013).



Fig. 1: Formation of the input data of the model to describe the construction process

Experience of the countries with stable market economy shows that the economic efficiency of construction depends on the perfection of organization of works. Multifactorial nature of the construction works can be considered only by the proper scheduling. Minimum indexes of the work value and the timing in the schedule of their implementation depend on the correct distribution of manpower and technical resources between the works (Buvik and Rolfsen, 2015). Some scientific papers are dedicated to the issues of increasing the efficiency of scheduling.

Mukuka et al. (2015) revealed that extension of time, cost overruns, loss of profit, disputes, poor quality of work due to hurrying the project, creates stress to the client, acceleration losses, bad reputation with contraction team, claims and delay in getting profit by the client were the major effects of construction projects schedule overruns.

Ghoddousi et al. (2013) stated that minimizing both project time and cost is an important matter in today's competitive environment. Therefore, tradeoff between project time and cost is necessary. In projects, each activity can be started at different time points, depending on its precedence relationship and resource availability. Also cost and duration of the activities could be changed depending on the allocated resources.

Kaiafa and Chassiakos (2015) considered that an optimization method for multiobjective resourceconstrained scheduling which evaluates several resource-duration alternatives within each activity. As a result of the development of alternative project scheduling, it is rendered to choose the most optimal variant of construction works that meets the client's requirements.

Fang (2014) proposed to develop the algorithm and model performance, and also provided several project instances with different network structures and realizations to discuss the factors on total cost.

Gálvez and Capuz-Rizo (2016) wrote about the definition of interdependencies and duration of 
activities, communication times and the level of overlap between activities for project scheduling. And also noted that these parameters have epistemic uncertainties that can affect project scheduling. They applied different global sensitivity analysis techniques to identify the parameters that had the greatest effect on project scheduling.

Chen et al. (2012) proposed an intelligent scheduling system that uses simulation techniques to distribute resources and assigns the different levels of priorities to different activities in each simulation cycle to find the near-optimal solution.

Francis (2015) and Stashevskaya and Ruzbeh (2014) in their works pointed out the importance of graphical modelling and data visualization to communicate information clearly and effectively through graphical means. All the above works are dedicated to improve the economic feasibility of construction projects.

However, Bragadin and Kähkönen (2015) accentuated their work to the issues of Safety, Space and Structure: the planned process should provide a safe working environment to construction workers, sufficient space to perform construction activities and the required sequence of construction operations and project phases. These factors have the important social significances.

Analysis of the works of leading scientists has shown that the existing approaches to the construction scheduling do not provide a complete layout to achieve the ultimate goal - socio-economic feasibility of construction projects.

\section{Perfection of construction scheduling}

The link nature between the simple technological processes has a direct effect on the duration of construction works. Depending on the nature of such links can be set up in-line, parallel and parallel-line method of conducting works. All of this information is the input point for the creation of socio-economic model to describe the planning and management process of construction of a particular project or complexes. In modern engineering practice of the construction scheduling one of the following programs are used:

- Microsoft Project, which is the leader in number of users;

- Open Plan - an analog of the Microsoft Project;

- Primavera Project Planner;

- Cobra - a financial program for budget planning;

- Spider Project - a software that takes into account the Russian peculiarities for investment project;

- Project Expert and others.

And also can be selected the Chief-Builder and the Plan WIZARD, which allow to use the estimate and normative bases to obtain the project valuation at a pre-stage.

The existing software allows automating the planning processes in project management (Maheswari et al., 2015).
However, each of them focuses on different purposes. To improve the construction scheduling methods by accounting the works at the level of simple technological processes we propose to introduce a model of space-technological structure of the processes of construction projects. Such models take into account the specifics of a particular construction work and enable to use a unified planning at a level of simple technological processes (Figs. 2-6). When applying this method, it is possible to obtain a significant reduction in the duration of construction works, and also to improve the efficiency of collaborative works of all subcontractors.

One of the features of construction work is the fixed nature of construction in contrast to all other sectors of the real sector. It is necessary to coordinate on the labor input or on the implementation timing of all major and auxiliary processes to unify the consideration of works at a level of simple technological processes by the contractors. It is also necessary to establish the clear criteria to estimate the determining boundaries of performance of the simple technological processes.

Implementation of this requirement in conditions of construction works can not only lead to a reduction in execution time, but also to the possibility of reduction of accidents in construction site.



Fig. 2: Preparation of the input information for working out of construction schedule, taking into account the fixed nature of construction

Another feature of the construction industry, which should be taken into account in scheduling, is the area of the object being built. Linear dimensions of construction works are many times higher than the anthropometric features of the human being. It sets tasks for arrangement of horizontal and vertical communications. It requires some additional arrangements for the storage facilities. All these tasks are proposed to solve on the level of simple technological processes. 
Significant Linear Dimensions of the Construction works



Consideration of the work limitations on the adjacent frontmodules if a dangerous zone is adjacent.

Consideration of the work related to the technological capabilities and material resources.

Fig. 3: Preparation of the input information for working out of construction schedule, taking into account the linear dimensions of the construction works

Construction of each project requires drawing up the individual solutions for preparatory draft. It is due to the necessity of taking into account the specific features of the area and the development of engineering infrastructure, such as:

- dispersal of construction projects over a large territory;

- during the works in cramped conditions, inability to accommodate construction materials even for a day ahead;

-interchangeability of working procedures, structures and resources;
- lack of precision in presentation of documents for organizational and technological preparation;

- construction of very complicated and unique projects with a tight schedule of designing and preparatory works;

-impossibility of reserving the certain material resources.

In addition, if the construction is carried out in urban areas, there may occurs some limitations on the size of the construction site. Applying the accumulated design solutions at the level of simple technological processes can be optimized the consideration of these factors.

Consideration of the changing nature, characteristics and volumes of the construction works at the level of simple technological processes allows to minimize the duration of the work at the projects, and as a consequence, reduce the cost of construction.

\begin{tabular}{|c|c|c|}
\hline \multicolumn{3}{|c|}{ Links to the Construction Site } \\
\hline \multirow{3}{*}{$\begin{array}{l}\text { Dependency of the } \\
\text { preparatory works on } \\
\text { the local topography, } \\
\text { transportation and } \\
\text { engineering } \\
\text { infrastructure of the } \\
\text { area. Dependency of } \\
\text { the zero cycle works } \\
\text { on the hydrogeological } \\
\text { conditions. }\end{array}$} & $\begin{array}{l}\text { Large volumes of } \\
\text { setup-concluding, } \\
\text { transportation and } \\
\text { auxiliary works. }\end{array}$ & $\begin{array}{l}\text { Possibility of } \\
\text { the occurrence } \\
\text { of construction } \\
\text { works if the } \\
\text { cramped } \\
\text { conditions. }\end{array}$ \\
\hline & \multirow{3}{*}{$\begin{array}{l}\text { Separation of the } \\
\text { process of } \\
\text { preparatory works } \\
\text { to the level of } \\
\text { simple } \\
\text { technological } \\
\text { process with the } \\
\text { further association } \\
\text { to the overall } \\
\text { models. }\end{array}$} & \\
\hline & & \multirow{2}{*}{$\begin{array}{l}\text { Consideration } \\
\text { of the space } \\
\text { limitations for } \\
\text { the storage and } \\
\text { transportation } \\
\text { facilities. }\end{array}$} \\
\hline $\begin{array}{l}\text { Consideration of the } \\
\text { cliatic, hydrogeological } \\
\text { and seismic features of } \\
\text { the construction area. }\end{array}$ & & \\
\hline
\end{tabular}

Fig. 4: Preparation of the input information for working out of construction schedule, taking into account the links to the construction site

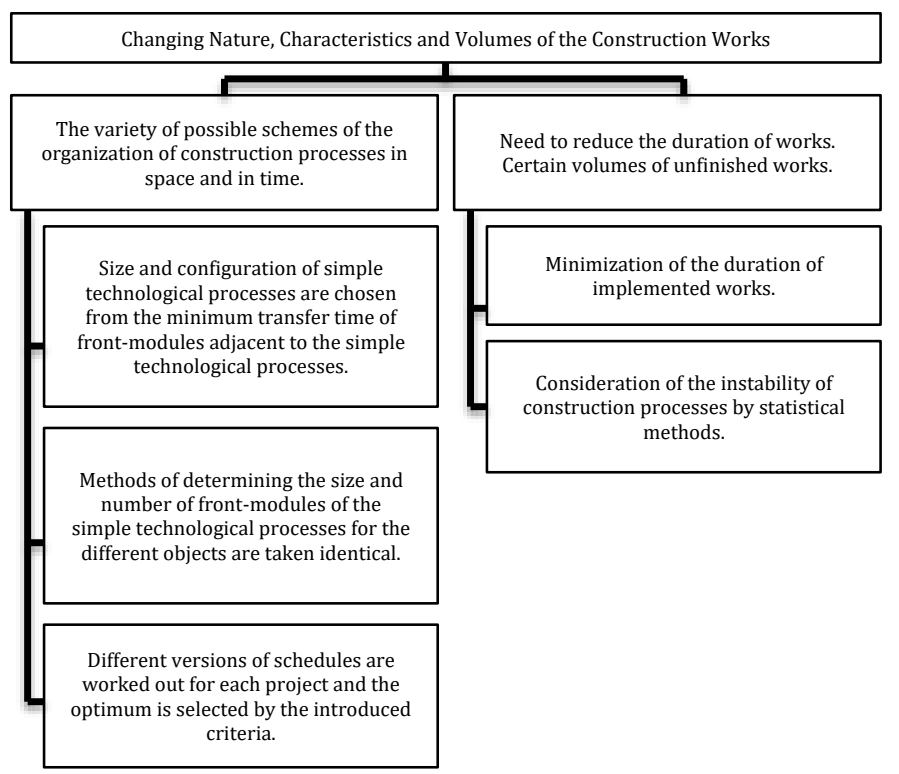

Fig. 5: Preparation of the input information for working out of construction schedule, taking into account the changing nature of construction works 
Large number of participators of construction works can lead to an imbalance of the quantity of the manpower, material and financial resources which are located together on the construction site. Each of the participants of the work process gets a set of unique professional competencies. It makes possible the use of his work only at a specific type of activity regardless of downtime due to the technological necessities. It is possible to optimize the resources by regulating the processes at the level of simple technological processes.

In the modern investment and construction business the main tendency is the division of works between the specialized subcontractors' construction companies. The main task of the chief contractor company is to work out the construction schedule that allows using the simple unified technological processes for working out of a model of spatial and technological structure of the construction process.

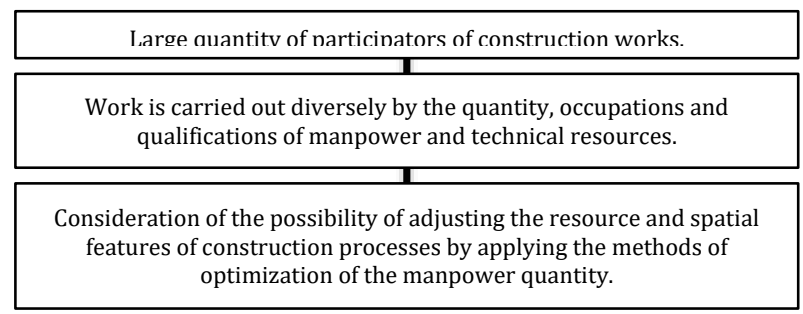

Fig. 6: Preparation of the input information for working out of construction schedule, taking into account the quantity of participators of construction works

\section{Results and discussion}

For approbation of the developed construction schedules a construction project was selected in Ramenskoe, Moscow region, Russia.

Construction Company "Garantia-Stroy" has been accumulated some experiences with the subcontractors in this locality at the dot building in the existing residential neighborhoods. Upon receiving the contract for construction of a new residential complex (Fig. 7), the construction company asked us to work-out the construction schedule.

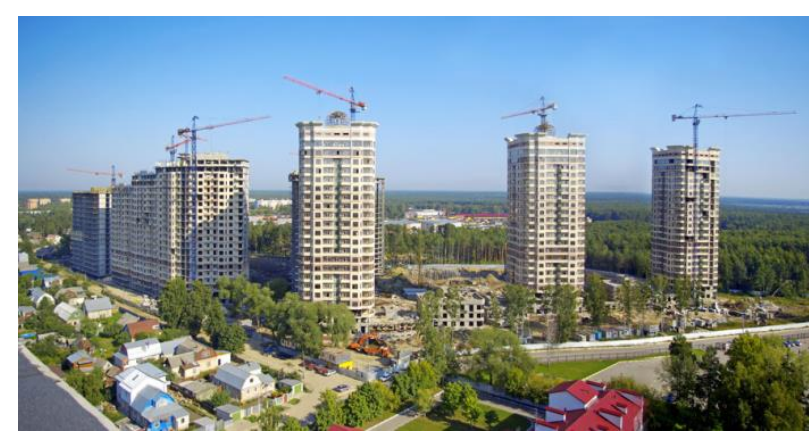

Fig. 7: The complex of residential buildings erected by the proposed construction schedule

At the work-out of construction schedule there was a task, by the conditions of investor, to minimize the quantity of manpower and technical resources, involved in certain simple technological processes and in the area of Ramenskoe at all.

An analysis of the data of work, material and financial resources of subcontractors in the performance of work on the constructed objects was conducted. Space-technological model of construction works was built in accordance to the following stages:

1) Initial data:

a. breakdown of the total complex of works on the simple technological processes;

b. determining the volume of work for each simple technological process;

c. determining the duration of work for each simple technological process;

2) Determination of a possible sequence of performing the simple technological processes;

3) Calculation of methods of the organization of performing the simple technological processes at the variety of sequences of their execution;

4) Selection of the rational variant of sequence of construction project of the residential complex by the criteria of time;

5) Calculation of options for the parallel-flow organization of works on the residential complex, and plotting with the help of software 'Spider Project';

6) Analysis and comparison of organizational and economic efficiency of construction in accordance to the option of construction schedule with the breakdown into simple technological processes and the schedule prepared by the classical method.

7) Selection of the most rational option, taking into account the duration of construction work and the financing possibilities.

The construction schedule of works with a breakdown into simple technological processes reduced the construction time by $11 \%$ compared to the plan that prepared by the classical method.

Resource information provided by the subcontractors allowed us to achieve an equal distribution throughout the whole duration of preparatory works on the demolition of old buildings in the area of Ramenskoe and construction of new projects. Working-out of construction schedule at the level of simple technological processes allowed us to optimize the scheduling parameters in designing of the following individual projects or their complexes, which allowed us to maintain the socio-economic feasibility of construction projects through the proper use of manpower and technical resources.

\section{Conclusion}

Pre-defined boundary factors on the technical requirements of works and available manpower, 
material and financial resources to each specialized subcontractor company allow to work without any stress, which have a social feasibility of construction projects. Main contractor determines the requirements for structural conjunction of various works and the sequence of their implementation, which allow reducing the construction time and properly distributing the manpower and technical resources between the works, and having an economic feasibility of construction projects.

Consequently, the improved methods of construction scheduling by considering the works at the level of simple technological processes can improve the organizational and economic feasibility of construction projects.

\section{References}

Bragadin MA and Kähkönen K (2015). Safety, space and structure quality requirements in construction scheduling. Procedia Economics and Finance, 21: 407-414.

Buvik MP and Rolfsen M (2015). Prior ties and trust development in project teams - A case study from the construction industry. International Journal of Project Management, 33(7): 1484-1494.

Chen SM, Chen PH, and Chang LM (2012). Simulation and analytical techniques for construction resource planning and scheduling. Automation in Construction, 21: 99-113.

Fang $\mathrm{Fu}$ (2014). Integrated scheduling and batch ordering for construction project. Applied Mathematical Modelling, 38(2): 784-797.

Francis A (2015). Graphical modelling classification for construction project scheduling. Procedia Engineering, 123: 162-168.
Gálvez ED and Capuz-Rizo SF (2016). Assessment of global sensitivity analysis methods for project scheduling. Computers and Industrial Engineering, 93: 110-120.

Ghoddousi P, Eshtehardian E, Jooybanpour S, and Javanmardi A (2013). Multi-mode resource-constrained discrete time-costresource optimization in project scheduling using nondominated sorting genetic algorithm. Automation in Construction, 30: 216-227.

Kaiafa S and Chassiakos AP (2015). A genetic algorithm for optimal resource-driven project scheduling. Procedia Engineering, 123: 260-267.

Maheswari JU, Charlesraj VPC, Goyal A, and Mujumdar P (2015). Application of relationship diagramming method (RDM) for resource-constrained scheduling of linear construction projects. Procedia Engineering, 123: 308-315.

Mukuka M, Aigbavboa C, and Thwala W (2015). Effects of construction projects schedule overruns: A case of the Gauteng Province, South Africa. Procedia Manufacturing, 3: 1690-1695.

Stashevskaya NA and Ruzbeh S (2014) Analysis of modern methods of optimization of construction scheduling. In the $7^{\text {th }}$ International Scientific and Practical Conference on Engineering Systems. Publishing House of the Peoples' Friendship University of Russia, Moscow, Russia: 55-68. Available online at: https://elibrary.ru/item.asp?id= 24327972

Stashevskaya NA, Malov AN, and Fateev DI (2013). ОРГАНИЗАЦИОННО>ТЕХНОЛОГИЧЕСКАЯ НАДЕЖНОСТЬ СТРОИТЕЛЬНОГО ПРОИЗВОДСТВА [Organizational and technical reliability of building production]. RUDN Journal of Engineering Researches, 1: 13-16. Available online at: http://journals.rudn.ru/engineering-researches/article/view $/ 4730 / 4184$

Taillandiera F, Taillandierb P, Tepelia E, Breyssea D, Mehdizadeha $\mathrm{R}$, and Khartabila F (2015) A multi-agent model to manage risks in construction project (SMACC). Automation in Construction, 58: 1-18. 